\title{
Organization of SNAREs within the Golgi Stack
}

\author{
Jörg Malsam and Thomas H. Söllner \\ Heidelberg University Biochemistry Center, 69120 Heidelberg, Germany \\ Correspondence: thomas.soellner@bzh.uni-heidelberg.de
}

Antero- and retrograde cargo transport through the Golgi requires a series of membrane fusion events. Fusion occurs at the cis- and trans-side and along the rims of the Golgi stack. Four functional SNARE complexes have been identified mediating lipid bilayer merger in the Golgi. Their function is tightly controlled by a series of reactions involving vesicle tethering and SM proteins. This network of protein interactions spatially and temporally determines the specificity of transport vesicle targeting and fusion within the Golgi.

\begin{abstract}
$A^{t}$ steady state, the Golgi maintains its strucAtural and functional organization despite a massive lipid and protein flow. A balanced anterograde and retrograde membrane flow are required to constantly recycle the transport machinery and cargo containers (vesicles). In the absence of efficient recycling, directional net cargo transport would cease and the Golgi would collapse. Thus, transport vesicles constantly leave and enter at both sides of the Golgi stack and bud and fuse along the rims of the cisternae. To maintain the compartmental identity, vesicle fusion occurs in a specific and orchestrated manner. These fusion events are mediated by a cascade of reactions centered around the membrane fusion proteins SNAREs (SNAP receptors) (Söllner et al. 1993b).
\end{abstract}

\section{SNARE COMPLEX ASSEMBLY AND DISASSEMBLY}

SNAREs represent a family of tail-anchored membrane proteins, whose individual members are localized to distinct intracellular compartments along the secretory and endocytic pathway (Jahn and Scheller 2006; Malsam et al. 2008). On a functional/topological basis, SNAREs can be classified as $\mathrm{v}$ - and t-SNAREs, because they are usually active on vesicles and target membranes (Söllner et al. 1993b). In the case of homotypic fusion, a clear distinction between the two compartments is not possible, however, the reaction mechanisms driving fusion are comparable to those of heterotypic fusion. On a structural basis, SNARE motifs, the hallmark signature characterizing all SNARE family members, provide the underlying principle to understand SNARE complex assembly and regulation (Fasshauer et al. 1998). Upon pairing of a v-SNARE with its cognate t-SNARE on opposing membranes, the SNARE motifs assemble to form trans-v/t-SNARE complexes, also termed SNAREpins, a process that occurs in a zipper-like manner starting at the amino-terminal membrane-distal ends and progressing toward the carboxy-terminal membrane-proximal regions of the SNAREs (Melia et al. 2002; Pobbati et al. 2006). This assembly

Editors: Graham Warren and James Rothman

Additional Perspectives on The Golgi available at www.cshperspectives.org

Copyright (C) 2011 Cold Spring Harbor Laboratory Press; all rights reserved; doi: 10.1101/cshperspect.a005249

Cite this article as Cold Spring Harb Perspect Biol 2011;3:a005249 
reaction pulls the two opposing membranes together to overcome the repulsive forces of the surrounding aqueous environment, which provides an energy barrier for lipid bilayer merger. Several in vitro and in vivo studies have established that SNAREs are sufficient to drive membrane merger, and thus SNAREs have been considered to be the minimal membrane fusion machinery (Weber et al. 1998; Hu et al. 2003). The fully assembled postfusion cis-SNARE complex, now located in a single lipid bilayer, becomes a substrate for SNAPs (soluble NSF attachment factors), which in turn recruit the hexameric ATPase NSF (N-ethylmaleimide sensitive factor) (Block et al. 1988; Whiteheart et al. 1993). Both SNAPs and NSF are cytosolic proteins acting on all cis-SNARE complexes at the various transport steps. ATP hydrolysis by NSF dissociates the SNARE complexes resulting in largely unstructured SNARE proteins, which now can be recycled for another round of transport (Söllner et al. 1993a; Mayer et al. 1996). Thus, membrane fusion is driven by protein folding ( $\mathrm{v}-/ \mathrm{t}-$ SNARE complex assembly), and a net input of energy (ATP hydrolysis) is required to unfold the SNAREs.

\section{SNARE STRUCTURE}

The SNARE motif is located in the cytosolic domain of the SNAREs and in close proximity to the trans-membrane domain (Fasshauer et al. 1998). An individual SNARE protein usually contains a single SNARE motif. Exceptions are members of the SNAP-25 subfamily, which contain two SNARE motifs joined in a single polypetide chain. The SNARE motif consists of a stretch of about 60-70 amino acids, which contains heptad repeats that have a propensity to form coiled-coil structures (Fig. 1). However, in the absence of a binding partner, SNARE motifs are largely unstructured (Fasshauer et al. 1997). When a functional (fusogenic) $\mathrm{v}$-/t-SNARE complex forms, four SNARE motifs assemble into a stable four-helix bundle (Sutton et al. 1998). Based on the presence of the heptad repeats, 16 stacked layers of amino acid side chains stabilize the four-helix bundle
(Fig. 1). With the exception of a central "0" layer, which usually contains either a hydrophilic glutamine or an arginine residue, all other layers are characterized predominantly by hydrophobic side chains. Based on the amino acid composition of the central layer and other structural features, the classification: $\mathrm{Q}_{\mathrm{a}^{-}}, \mathrm{Q}_{\mathrm{b}^{-}}, \mathrm{Q}_{\mathrm{c}^{-}}$, and R-SNAREs were introduced in addition to the topological/functional $\mathrm{v}$ - and t-SNAREs definition (Fasshauer et al. 1998). Functional SNARE complexes always contain one member of these four SNARE subfamilies.

For fusion to occur, the SNARE motif and the trans-membrane domain need to be directly coupled, indicating that the folding of the cytosolic SNARE motifs provides direct physical work on the lipid bilayer (Grote et al. 2000; McNew et al. 2000b). Indeed, the crystal structure analysis of the assembled neuronal $\mathrm{v}-/ \mathrm{t}-\mathrm{SNARE}$ complex, containing the transmembrane regions, revealed a helical extension of the SNARE motifs into the membrane (Stein et al. 2009).

Remarkably, most fusogenic SNARE complexes show a strict topological restriction. Thus, when a SNARE complex is built from its cognate $\mathrm{Q}_{\mathrm{abc}}{ }^{-}$and R-SNAREs, the SNAREs need to be distributed in a defined manner between the two membranes to be fused. In most cases, only one out of eight possible topological distributions appears to be functional as has been shown by in vitro reconstitution experiments (McNew et al. 2000a; Parlati et al. 2000). However, in the endosomal system, mediating homotypic fusion, other topological combinations have been found to fuse reconstituted liposomes (Zwilling et al. 2007). Biochemical studies have shown that t-SNAREs form stable subcomplexes, which function as templates for v-SNARE binding (Fasshauer and Margittai 2004). A functional t-SNARE complex always contains one molecule of the syntaxin/ $\mathrm{Q}_{\mathrm{a}}$-SNARE subfamily and usually comprises three partially assembled SNARE motifs, which in many cases match the $\mathrm{Q}_{\mathrm{abc}}{ }^{-}$ composition. (The syntaxin/ $\mathrm{Q}_{\mathrm{a}}$-SNARE and the nonsyntaxin t-SNARE components have also been called t-SNARE heavy and light 
A

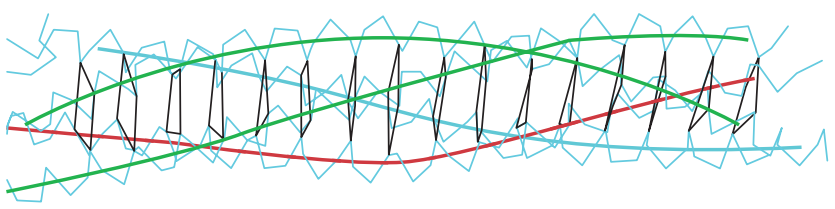

B

$\mathbf{Q}_{\mathbf{a}} \mid \begin{array}{ll}\text { Stx } & 18 \\ \text { Stx } & 5 \\ \text { Stx } & 16\end{array}$

$\mathbf{Q}_{\mathbf{b}} \mid \begin{aligned} & \text { SEC20 } \\ & \text { Membrin } \\ & \text { GOS28 } \\ & \text { VTIla }\end{aligned}$

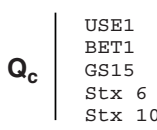

$\mathbf{R} \mid$\begin{tabular}{l|l} 
Sec22b \\
YKT6 \\
VAMP3 \\
VAMP4
\end{tabular}
$-7-6-5-4-3-2-1 \quad 0+1+2+3+4+5+6+7+8$

TM

DEVRQIEGRVVEISRLQEIFTEKVLQQEAEIDS IHQLVVGATENIKEGNEDIREAIKNNAGFR-VWILFFLVMCSFSLLFLDWYDSDTMQNIESTIVELGS IFQQLAHMVKEQEETI QR IDENVLGAQLDVEAAHSE ILKYFQSVTSNRWLMVKIFLILIVFFI IFVVFLA---
REIRQIVQSISDLNEIFRDLGAMIVEQGTVLDRIDYNVEQSCIKTEDGLKQLHKAEQYQKKNRKMLVILILFVIIIVLIVVLVGVKSR ESLMGISRMMAQQVQQSEEAMQSLVTSSRTILDANEEFKSMSGTIQLGRKLITKYNRRELTDKLLIFLALALFLATVLYIVKKRLFPFL
SSLQKVHNGMDDLILDGHNILDGLRTQRLTLKGTQKKILDIANMLGLSNTVMRLIEKRAFQDKYFMIGGMLLTCVVMFLVVQYT---
DHLRNSDRLIEETISIAMATKENMTSQRGMLKSIHSKMNLANRFPVNSLIQRINLRKRRS-LILGGIGICTILLLLYAFH----
RRLEAGYQIAVETEQIGQEMLENLSHDREKIQRARERLRETDANLGKSSRILTGMLRRIIQNRILLVILGIIVVITILMAITFSVRR-

KLAEEMLGLARSLKTNTLAAQSVIKKDNQTLSHSLKMADQNLEKLKTESERLEQHTQKSVNWLLWAMLI IVCFIFISMILFIRIMPKLK RLTESLRSKVTAIKSLSIEIGHEVKTQNKLLAEMDSQFDSTTGFLGKTMGKLKILSRGSOT--KLLCYMMLFSLFVFFII-YWIIKLRRMADSLASKVTRLKSLALEIDRDAEDQNRYLDGMDSDFTSMTSLLTGSVKRFSTMARSGQDNRKLLCGMAVGLIVAFFILSYFLSRART EQLELVSGSIGVLKNMSQR IGGELEEQAVMLEDFSHELESTQSRLDNVMKKLAKVSHMTSDRRQWCAIAILFAVLLVVLILFLVL----QQLEMVSGS IQVLKHMSGRVGEELDEQGIMLDAFAQEMDHTQSRMDGMLRKLAKVSHMTSDRRQWCAIAVLVGVLLLVLILLFSL----

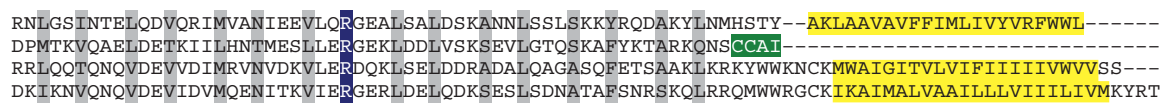

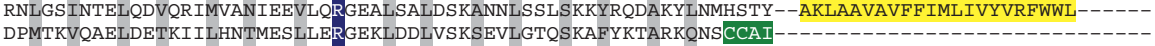
RRLQQTQNQVDEVVDIMRVNVDKVLERDQKLSELDDRADALQAGASOFETSAAKLKRKYWWKNCKMWAIGITVLVIFIIIIIIVWVVSS--DKIKNVQNQVDEVIDVMQENITKVIERGERLDELQDKSESLSDNATAFSNRSKQLRRQMWWRGCKI KAIMALVAAILLLVI I ILIVMKYRT

Figure 1. Structural organization of the SNARE four-helix bundle and SNARE motifs of ER and Golgi SNAREs. (A) Skeleton diagram of the synaptic SNARE four-helix bundle showing interacting layers (image is modified from Fasshauer et al. [1998] and reprinted, with permission, from the National Academy of Sciences (C) 1998). (B) SNARE motifs and membrane anchors of human SNAREs involved in ER and Golgi transport were aligned using the MULTALIN program (Corpet 1988). Interacting layers are shown in gray; amino acids in "0" layer and trans-membrane regions are highlighted in color. Ykt6 contains a CAXX box, which is farnesylated and palmitoylated. The $\mathrm{Q}_{\mathrm{a}^{-}}, \mathrm{Q}_{\mathrm{b}^{-}}, \mathrm{Q}_{\mathrm{c}^{-}}$, and R-SNARE classification is shown and SNAREs are listed according to their position in the secretory pathway: SEC20 (NP_053583.2), USE1 (NP_060937.1), BET1 (NP_005859.1), GS15 (AFF37877.1), syntaxin 6 (syx6) (CAA05177.1), syntaxin 10 (syx10) (AAC05087.1), SEC22b (NP_004883.2), YKT6 (NP_006546.1), VAMP3 (NP_004772.1), VAMP4 (NP_003753.2), syntaxin 18 (BAA95213.1), syntaxin 5 (AAC71078.1), syntaxin 16 (syx16) (AAC05647.1).

chains, respectively.) Other SNARE topologies might form transient SNARE complexes, which however are not stable enough to allow SNAREpin formation across membranes, or provide not enough energy to drive membrane fusion. This topological restriction has important implications for the regulation of membrane fusion, because a functional t-SNARE complex will only form when all three t-SNARE components reside within the same membrane. Furthermore, even when all three cognate SNARE components are within the same membrane, regulatory components still control the assembly of the t-SNARE complex and subsequent $\mathrm{v}$-t-SNARE complex formation. Syntaxins $/ \mathrm{Q}^{-}$ SNAREs are key control sites for SNAREcomplex assembly. Like many other SNAREs, they contain regulatory domains, which are found at their amino-termini and control SNARE motif accessibility and structure. The type of regulatory domains differs between SNARE subfamilies (Malsam et al. 2008).

Based on a comparative analysis of several model organisms, the four subfamilies can be further divided into 20 distinct conserved functional subgroups, which might represent the minimal repertoire of a proto-eukaryotic cell (Kloepper et al. 2007). During evolution, the SNARE sets were modified by duplication and diversification (Dacks and Field 2007; Kloepper et al. 2007). In particular, the SNARE repertoire in the endosomal and exocytic transport steps has undergone a substantial expansion, most likely to adapt to the rising complexity of these 
trafficking routes in metazoa. By contrast, a very limited number of different SNAREs operates at the endoplasmic reticulum and Golgi complex, suggesting that the initial fusion steps of the secretory route are highly conserved through evolution (Kienle et al. 2009).

\section{GOLGI SNARES}

The Golgi of mammals and plants is a highly polarized compartment, which is comprised of at least three distinct cisternae: cis, medial, and trans (Farquhar and Palade 1998). On the cis-side, the Golgi is preceded by the intermediate compartment (IC), (also named ER-Golgi intermediate compartment [ERGIC] or cis-Golgi network [CGN]), which receives membrane transport intermediates from the endoplasmic reticulum (ER) (AppenzellerHerzog and Hauri 2006). On the trans-side, the Golgi is succeeded by the trans-Golgi Network (TGN), which obtains transport vesicles from two distinct endosomal compartments: the early and late endosomes. Thus, in the simplest model, these three membrane trafficking steps that deliver material to the Golgi require three different v-/t-SNARE complexes. Additional SNARE complexes might be required to mediate vesicular transport at the rims of the cisternae, functioning in the retrieval of Golgi resident proteins and the anterograde transport of cargo in a percolating fashion within the Golgi stack. Because of variable numbers of cisternae within different cell types, and the genetic restriction of SNARE diversity, it naturally follows that one or a few SNARE complexes mediate inter-cisterna transport. To date, a total of four functional SNARE complexes have been identified in association with the Golgi (Fig. 2). A fifth complex, which mediates retrograde transport to the ER is mentioned here, because the Golgi contains SNAREs involved in this transport step.

The majority of Golgi-localized SNARE complexes and their individual components have been analyzed in great detail in in vitro and in vivo studies. Reconstituted membrane fusion assays have provided evidence that among 147 tested SNARE complexes, which could theoretically form at the Golgi, only two distinct SNARE complexes are capable of driving membrane fusion (McNew et al. 2000a; Parlati et al. 2000; Parlati et al. 2002). Remarkably, these studies also revealed that one particular SNARE protein can operate in two different complexes, indicating that nature uses a combinatorial code to make efficient use of a limited number of genetically encoded SNAREs (Parlati et al. 2002; Shorter et al. 2002). Both of these Golgi SNARE complexes share the same syntaxin $/ Q_{a}$ molecule: syntaxin 5 in mammals, Sed5p in yeast (Parlati et al. 2002). One complex consists of syntaxin 5/Sed5p, membrin/Bos1p (also known as GS27) and ERS24/Sec22p, which assemble to form the t-SNARE, and rBet1/Betlp functioning as the cognate $\mathrm{v}$ SNARE (Fig. 2) (Xu et al. 2000). In the second complex, syntaxin 5/Sed5p forms a different t-SNARE with GOS28/Gos1p (also known as GS28) and Ykt6/Ykt6p to create a binding site for the cognate v-SNARE Gs15/Sft1p. Whereas the former complex is implicated in transport from the ER to the Golgi, and possibly in intraGolgi transport between subsequent cisternae within the Golgi stack, the latter complex might exclusively function in COPI-dependent intraGolgi transport (Newman and Ferro-Novick 1987; Newman et al. 1990; Shim et al. 1991; Hardwick and Pelham 1992; Subramaniam et al. 1996; Zhang et al. 1997; Cao and Barlowe 2000; Zhang and Hong 2001; Xu et al. 2002; Volchuk et al. 2004). The distribution of these SNAREs within the Golgi in budding profiles and COPI-coated vesicles was also analyzed by electron microscopy (Nagahama et al. 1996; Paek et al. 1997; Orci et al. 2000; Volchuk et al. 2004). By quantitative analysis, syntaxin 5 has been shown to distribute evenly throughout the stack, confirming its role as the general Golgi syntaxin/ $Q_{a}$ SNARE. By contrast, a comparison of the two specific $\mathrm{v}$-SNAREs revealed that they have opposite distributions within the stack. Whereas the v-SNARE GS15 is present in a gradient of increasing concentration toward the trans-face of the stack, its counterpart Bet1 progressively decreases in concentration from the CGN toward the trans-face (Fig. 2) (Volchuk et al. 2004). In fact, the distribution of both 


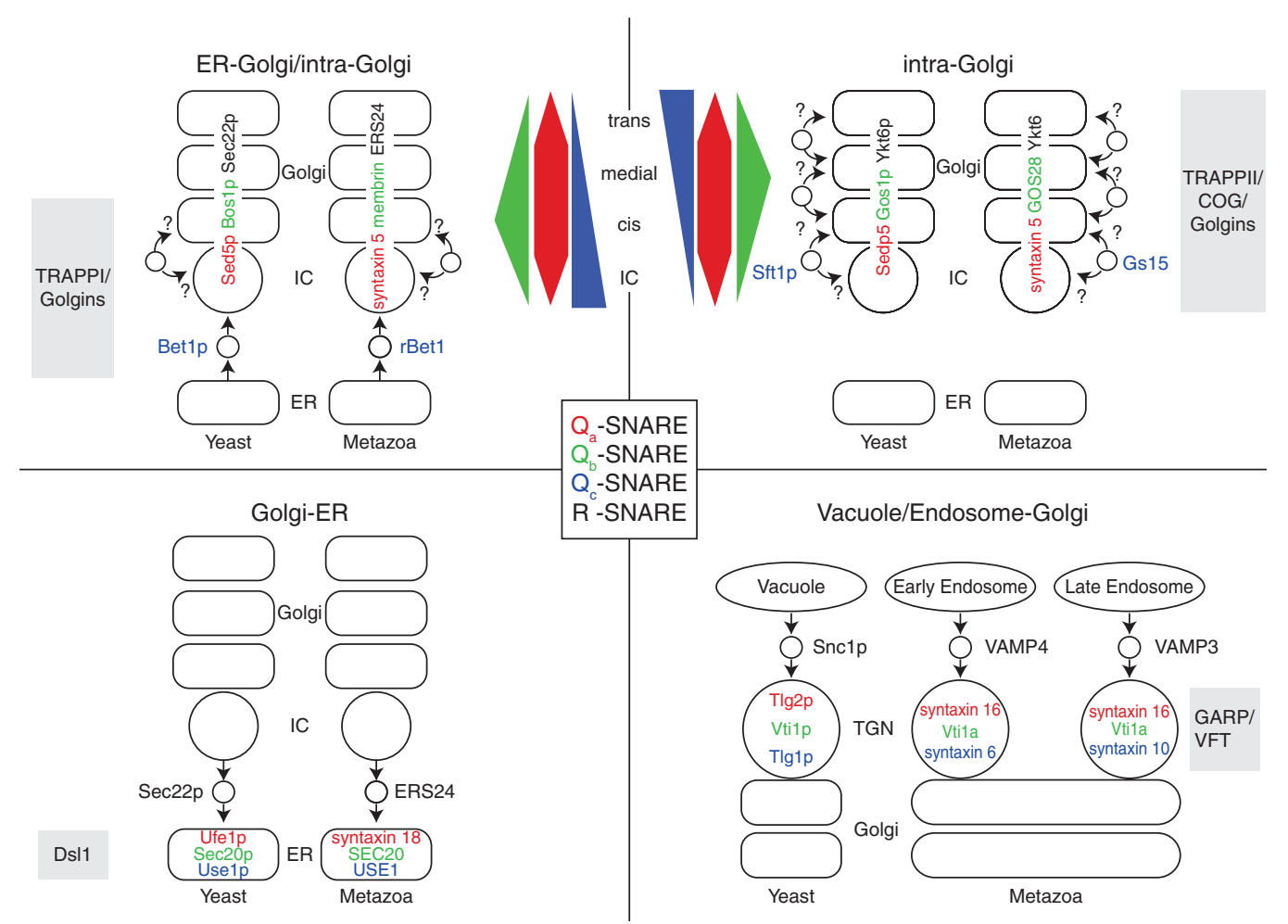

Figure 2. The localization and assignment of SNAREs and tethers to distinct membrane-trafficking steps at the Golgi of mammals and yeast. Four different sets, each containing one member of $\mathrm{Q}_{\mathrm{a}^{-}}, \mathrm{Q}_{\mathrm{b}^{-}}, \mathrm{Q}_{\mathrm{c}^{-}}$, and R-SNAREs mediate delivery to and transport within the Golgi. According to a morphological and quantitative analysis, the local distribution of some SNAREs involved in intra-Golgi transport is displayed. Tethering components are highlighted in gray. (ER: endoplasmic reticulum, IC: intermediate compartment, TGN: trans-Golgi network.)

v-SNAREs together with their cognate $\mathrm{Q}^{-}$ SNAREs across the Golgi appears as a mirror image and supports the concept that these SNARE complexes mediate membrane trafficking in opposite directions. In immunoprecipitation studies, syntaxin 5 has been detected in a variety of other noncognate complexes, but these might form spontaneously in an unspecific manner only after detergent lysis (Tsui et al. 2001). When reconstituted into liposomes, these noncognate complexes are not fusogenic (Parlati et al. 2002). If such noncognate SNARE complexes form in significant amounts in vivo is unclear. A spatial separation into membrane subcompartments, in combination with a proteinaceous machinery controlling SNARE complex assembly, might efficiently prevent the formation of nonfunctional complexes. Such complexes might also become substrates for SNAP and NSF, resulting in complex disassembly. Nevertheless, it has been shown in in vitro studies that noncognate SNARE complexes can affect membrane fusion (Varlamov et al. 2004). A reconstituted liposome fusion assay revealed that the cis-Golgi SNAREpin was inhibited by the addition of SNAREs that localize to the late-Golgi. Conversely, the late-Golgi SNAREpin was inhibited by the addition of cis-Golgi SNAREs. Because both SNARE complexes form gradients of opposite distributions within the stack, cognate SNAREs greatly outnumber SNAREs that are concentrated at the other end of the stack. Although this situation would favor the formation of cognate SNAREpins, SNAREs meant to function at the other end of the Golgi would become sequestered. 
Thus, such inhibitory i-SNAREs may be an effective tool to sharpen the continuous gradient of SNAREs within the Golgi stack. The physiological relevance of this concept remains to be established. A systematic study analyzing the presence of SNARE (sub) complexes at steady state within the Golgi stack in living cells has been difficult because of the limited spatial resolution of light microscopy. However, advances in microscopic techniques in combination with the introduction of site-specific fluorescent labels showing FRET will make such an endeavor possible in the near future.

The $Q_{a}$-SNARE syntaxin 5/Sed5p is not the only Golgi SNARE that is found in different functional complexes. As already mentioned, the R-SNARE Sec22p functions together with syntaxin $5 / \operatorname{Sed} 5 \mathrm{p}$ and membrin/Bos1p as t-SNARE in anterograde transport from the ER to the Golgi. Sec22p is also part of a SNARE complex, which mediates retrograde transport from the Golgi to the ER. This complex contains the syntaxin 18/Ufelp, SEC20/Sec20p, and USE1/Uselp as cognate SNARE components (Lewis et al. 1997; Hatsuzawa et al. 2000; Burri et al. 2003; Dilcher et al. 2003). Although, USE1 does not contain an R or a $\mathrm{Q}$ in the central layer of the SNARE motif, it has been classified as a Q-SNARE family member based on other criteria (Fasshauer et al. 1998; Dilcher et al. 2003). If Sec22p functions in this complex as a $\mathrm{v}$ - or t-SNARE remains to be shown. This issue could be directly resolved with liposome reconstitution experiments testing which topological SNARE combination is fusogenic. Nevertheless, an in vitro assay measuring retrograde transport from the Golgi to the ER already indicates that Sec22p and potentially Bet 1 can function as retrograde-directed v-SNAREs (Spang and Schekman 1998). A study analyzing the interaction of regulatory proteins with components of the retrograde Golgi-ER SNARE complex further supports that Sec22p operates as a v-SNARE (Kraynack et al. 2005). Thus, a single SNARE protein might function as part of a t-SNARE in one direction and as v-SNARE binding to a distinct t-SNARE in the opposite transport reaction.

The remaining two SNARE complexes (syntaxin 16/Vtila/syntaxin 6/VAMP4 and syntaxin 16/Vtila/syntaxin 10/VAMP3) are localized to the TGN and share two components in the corresponding t-SNARE subcomplexes (syntaxin 16/Vtila) (Mallard et al. 2002; Ganley et al. 2008). Thus, the presence of either syntaxin 6 or syntaxin 10 in these two t-SNARE complexes apparently provides enough information to specify by itself or in connection with other factors, if either VAMP4 or VAMP3 liposomes will fuse with the TGN. The syntaxin 16/Vtila/syntaxin 6/VAMP4 complex is involved in retrograde transport from early endosomes and the syntaxin 16/Vtila/syntaxin 10/ VAMP3 complex in retrograde transport from late endosomes (Ganley et al. 2008). In yeast, the $\operatorname{Tlg} 2 \mathrm{p} / \mathrm{Vtil} \mathrm{p} / \mathrm{Tlg} 1 \mathrm{p} /$ Snclp complex is implicated in retrograde transport to the TGN (Holthuis et al. 1998; Paumet et al. 2001).

\section{SNARE LOCALIZATION}

Because SNAREs show compartmental specificity and provide the road map for membrane trafficking, mechanisms must exist that target SNAREs to their final destinations and retain them in place. Two types of localization signals are involved in this process.

First, the membrane anchors of SNAREs, in particular the length and the degree of hydrophobicity of the trans-membrane domain (TMD) play a role. Distinct compartments along the secretory pathway differ in their lipid bilayer thickness, which increases toward the plasma membrane (Bretscher and Munro 1993; Munro 1995; Reggiori et al. 2000). In the case of the ER syntaxin $/ \mathrm{Q}_{\mathrm{a}}$-SNARE Ufelp, it has been shown that alterations in the amino acid composition, or an increased length of the TMD result in mislocalization of this t-SNARE component (Rayner and Pelham 1997). Ykt6, functioning in intra-Golgi transport, lacks a trans-membrane region but it is palmitoylated and farnesylated and contains a longin domain, which together determine the intracellular distribution of Ykt6 (Fukasawa et al. 2004; Meiringer et al. 2008). In addition, membrane subdomains and lipid interactions might play a role in SNARE localization. In the case of syntaxin 1, a syntaxin/ $\mathrm{Q}_{\mathrm{a}}$-SNARE involved 
in regulated exocytosis, cholesterol-dependent clusters have been observed in the plasma membrane (Lang et al. 2001; Sieber et al. 2007). The partitioning of Golgi SNAREs into membrane microdomains has not been determined yet.

The second type of SNARE sorting signals mediates the direct and specific binding to distinct vesicle coat components, which drive vesicle budding, cargo sorting, and determine the vesicle size (see Popoff et al. 2011). This type of interaction becomes of particular importance, when SNAREs have already reached their final destination and now function as fusion machinery, e.g., as a v-SNARE at a defined trafficking step. In this case, a budding vesicle needs to incorporate a "functional" $\mathrm{v}$-SNARE to allow the fusion with the target compartment, because vesicles lacking SNAREs would become dead end transport intermediates. In the early secretory pathway, SNAREcoat interactions have been intensively studied in the anterograde ER-Golgi transport step. In this case, COPII coated vesicles bud at the ER and can fuse either with each other in a homotypic fashion generating the cis-Golgi network (CGN) or with the CGN (Xu and Hay 2004). Indeed, COPII vesicles contain all SNAREs required to form the functional complex (Sed5p, Sec22p, Bos1p, and Bet1p) for this fusion step. In vitro reconstituted budding assays revealed that Sec22p and Boslp were enriched in COPII vesicles (Matsuoka et al. 1998). By contrast, the syntaxin $/ Q_{a}-S N A R E$ Ufelp, which forms a functional SNARE complex with Sec20p, Sec22p, and Use1p for retrograde Golgi-ER transport, was excluded from these vesicles. Betlp and Boslp interact with the COPII subunits Sec23/Sec24 and in the presence of either GTP or GDP with the GTPase Sarlp, which in its GTP-bound state recruits COPII-coats onto the ER-membrane (Springer and Schekman 1998). Remarkably, structural analyses suggest that COPII coats selectively package the active $\mathrm{v}$ - and t-SNAREs into budding COPII vesicles. The sorting signals are short peptides, which provide low affinity interactions with the coat components, and their availability depends on the conformational state of the SNARE (Mossessova et al. 2003).
Whereas the sorting sequence of the v-SNARE Bet1p is exposed in the free $\mathrm{v}$-SNARE but sequestered in the four-helix SNARE bundle, the sorting signal of Sed5p is hidden in an autoinhibitory Sed5p conformation, but is accessible in the Sed5p/Bos1p/Sec22p t-SNARE complex (Mossessova et al. 2003). This data indicates that the vesicle coat not only selects but also sequesters cognate v- and t-SNAREs in their active conformation and thus primes these vesicles for homotypic fusion.

Such structural information is not available for COPI-vesicles. Nevertheless, morphological and biochemical studies show that SNAREs are also recruited into COPI vesicles. Interactions of Bet1p and Sec22p with Glo3p and Arf1 have been reported (Rein et al. 2002). In addition to SNARE interactions, Glo3p also binds cargo proteins, COPI coat proteins, and functions as a GTPase-activating protein for Arf1p, which in its GTP-bound state recruits COPI coats (coatomer) to the Golgi. These interactions provide an interesting analogy to the recruitment of SNAREs into COPII vesicles, in which Sec23 functions as GTPase-activating protein for Sarlp and together with Sec24 recruits SNAREs, cargo, and the COPII proteins (Springer and Schekman 1998; Mossessova et al. 2003). Furthermore, Arf1 itself in its activated GTPbound state is capable of selectively binding the SNAREs GS15, Ykt6, and membrin, but not GOS28 (Honda et al. 2005; Lee et al. 2005). Nevertheless, GOS28 is enriched at Golgi rims and in COPI vesicles, but it is unclear whether GOS28 is recruited into COPI vesicles by direct coat protein interactions or by a stochastic process (Nagahama et al. 1996). In contrast, the membrane surface concentration of syntaxin 5 in COPI vesicles is twofold lower than in the Golgi stack, which is consistent with a requirement for $\mathrm{t}-\mathrm{SNAREs}$ and in particular syntaxin/ $\mathrm{Q}_{\mathrm{a}}$-SNAREs in the cisternae (Fig. 2) (Volchuk et al. 2004). Furthermore, in COPI vesicles, the concentrations of v-SNAREs and t-SNARE light chains exceed the concentration of syntaxin 5 at least by a factor of 2 . This ratio might ensure that excess free v-SNAREs are available for membrane fusion, whereas the t-SNARE components found in the same 
vesicle might cycle as cargo through the Golgi stack. In the cisternal maturation/progression model, in which cisternae form at the cis-Golgi, progress along the Golgi, and finally disassemble at the trans-Golgi, t-SNARE components need to be present in retrograde-directed COPI vesicles to ensure fusion machinery recycling (see Glick and Luini 2011).

Likewise, some of the three potential v-SNAREs (Sec22p, Bet1p, GS15p) present in a single COPI vesicle might travel as inactive cargo proteins in the process of being recycled between compartments. Alternatively, the individual v-SNAREs might be located to separate COPI vesicle populations, fusing either with the ER, the CGN/cis-Golgi, or at the rims of the Golgi stack. This question still remains to be resolved and will require the isolation of COPI vesicle using antibodies directed against individual v-SNAREs.

Altogether, SNAREs seem to be recruited into both COPII- and COPI-coated vesicles by a similar mechanism that requires interactions with coat components, Arfs and Arf-GAPs. Interestingly, the cold-sensitive phenotype of a Glo3 deletion mutant can be rescued by the overexpression of Bet1p, Bos1p, and Sec22p indicating that in the absence of a selective SNARE uptake mechanism, the stochastic incorporation of SNAREs into transport vesicles can suffice to ensure fusion competence and cell survival (Poon et al. 1999).

Following vesicle budding, pinching off, and uncoating, a vesicle fuses with its target compartment requiring the presence of all three t-SNARE components in a functionally active conformation. The assembly of a t-SNARE complex is mediated by regulatory proteins, which also function as transport step-specific vesicle tethering components. Thus, the location and type of tether make an important contribution, where a functional t-SNARE complex forms.

\section{SNARE INTERACTIONS WITH TETHERS}

Prior to SNAREpin formation, transport vesicles are captured by two types of membrane tethers (Sztul and Lupashin 2009). One family consists of coiled-coil proteins, and the members associated with the Golgi are named Golgins (see Munro 2011). The other family contains heterogeneous assemblies of multisubunit protein complexes, which operate not exclusively at the Golgi, but also on other organelles. The relevant multisubunit complexes associated with the ER and the Golgi are: Dsl1, TRAPPI/II, COG, and GARP/VFT (see Table 1). Many of these proteins directly bind specific t-SNARE components, either COPI or COPII vesicle coats, and interact in a GTPdependent manner with distinct compartment-specific small GTP binding proteins called Rabs (Stenmark 2009).

The TRAPPI and TRAPPII complexes differ significantly from the other multisubunit tethers, because they function as guanine nucleotide exchange factors (GEF) for Rabs and do not directly bind SNAREs. The TRAPPI complex is localized at the cis-side of the Golgi and is implicated in anterograde transport from the ER to the Golgi and COPII vesicle tethering (Sacher et al. 2001; Kim et al. 2006). It functions as a GEF for the Rab protein Ypt1 (Jones et al. 2000; Wang et al. 2000; Sacher et al. 2001). TRAPPII is implicated in intra Golgi and retrograde endosome-to-TGN transport (Cai et al. 2005). It interacts with COPIcoats and functions as a GEF for Ypt1 and Ypt31p/Ypt32p (Morozova et al. 2006). Thus, the GEF activities of TRAPPI/II complexes recruit specific Rab proteins to budding COPII and COPI vesicles, respectively.

The GARP or Vps fifty-three (VFT) complex is implicated in retrograde transport from early and late endosomes to the TGN (Siniossoglou and Pelham 2001; Conibear et al. 2003; Quenneville et al. 2006). It consists of four proteins (Vps51/52/53/54). In yeast, Vps51 directly binds the amino-terminal domain of Tlg1p and may release the putative autoinhibition of the amino-terminal domain of Tlglp thus favoring t-SNARE complex formation (Siniossoglou and Pelham 2001; Conibear et al. 2003; Fridmann-Sirkis et al. 2006). In mammals, the GARP/VFT complex interacts with the SNARE motifs of syntaxin 6, syntaxin 16, and VAMP4 (Perez-Victoria and Bonifacino 2009). In addition, it binds the Rab protein 
Organization of SNAREs within the Golgi Stack

Table 1. Multisubunit tethering proteins and interacting partners

\begin{tabular}{|c|c|c|c|c|c|c|}
\hline Multisubunit tether & SNARE & Rab & Coat & SM & $\begin{array}{c}\text { Coiled-coil } \\
\text { tether }\end{array}$ & References \\
\hline $\begin{array}{l}\text { Dsl1/ZW10 (Dsl1, } \\
\text { Tip20, Dsl3) }\end{array}$ & $\begin{array}{l}\text { Ufe1/Sec20/Use1, } \\
\text { syntaxin } 18\end{array}$ & & $\begin{array}{l}\text { COPI } \\
\qquad \begin{array}{l}(\alpha-\mathrm{COP} \\
\delta-\mathrm{COP})\end{array}\end{array}$ & & & $\begin{array}{l}\text { Lewis et al. 1997; } \\
\text { Frigerio 1998; } \\
\text { Reilly et al. 2001; } \\
\text { Andag and } \\
\text { Schmitt 2003; } \\
\text { Hirose et al. 2004; } \\
\text { Arasaki et al. 2006 }\end{array}$ \\
\hline $\operatorname{COG}(\operatorname{Cog} 1-8)$ & $\begin{array}{l}\text { Sed5/Ykt6/Gos1, } \\
\text { Sed5, } \\
\text { syntaxin 5, } \\
\text { GOS28 }\end{array}$ & $\begin{array}{l}\text { Ypt1, } \\
\text { Ypt6, } \\
\text { Rab6, } \\
\text { Rab30, } \\
\text { Rab41 }\end{array}$ & $\begin{array}{l}\text { COPI } \\
\qquad \begin{array}{l}(\beta-\mathrm{COP}, \\
\gamma-\mathrm{COP})\end{array}\end{array}$ & Sly1 & $\begin{array}{l}\text { p115, } \\
\text { GM130 }\end{array}$ & $\begin{array}{l}\text { Ram et al. 2002; } \\
\text { Suvorova et al. } \\
\text { 2002; Zolov and } \\
\text { Lupashin 2005; } \\
\text { Shestakova et al. } \\
\text { 2007; Sohda et al. } \\
\text { 2007; Fukuda et al. } \\
\text { 2008; Laufman } \\
\text { et al. } 2009\end{array}$ \\
\hline $\begin{array}{l}\text { GARP/VFT } \\
\quad(\text { Vps51, Vps52, } \\
\text { Vps53, Vps54) }\end{array}$ & $\begin{array}{l}\text { Tlg1, } \\
\text { syntaxin } 10, \\
\text { syntaxin } 16, \\
\text { syntaxin } 6 \text {, } \\
\text { VAMP4 }\end{array}$ & Ypt6 & & & & $\begin{array}{l}\text { Siniossoglou and } \\
\text { Pelham 2001, } \\
\text { 2002; Conibear } \\
\text { et al. 2003; Liewen } \\
\text { et al. 2005; } \\
\text { Perez-Victoria } \\
\text { and Bonifacino } \\
2009\end{array}$ \\
\hline $\begin{array}{l}\text { TRAPP I } \\
\text { (Bet3, Bet5, } \\
\text { Trs20, Trs23, } \\
\text { Trs31, Trs33) }\end{array}$ & & Ypt1 & $\begin{array}{l}\text { COPII } \\
\qquad(\operatorname{Sec} 23)\end{array}$ & & & $\begin{array}{r}\text { Wang et al. 2000; } \\
\text { Cai et al. } 2007\end{array}$ \\
\hline $\begin{array}{l}\text { TRAPPII } \\
\quad \text { (TRAPPI+Trs65, } \\
\text { Trs120, Trs130) }\end{array}$ & & $\begin{array}{r}\text { Ypt1, Rab1, } \\
\text { Ypt31/32 }\end{array}$ & $\begin{array}{l}\text { COPI } \\
\qquad(\gamma-\mathrm{COP})\end{array}$ & & & $\begin{array}{l}\text { Jones et al. 2000; } \\
\text { Yamasaki et al. } \\
2009\end{array}$ \\
\hline
\end{tabular}

Ypt6p (Siniossoglou and Pelham 2001). Thus, the GARP complex could tether vesicles containing Rab6/Ypt6p to preassembled t-SNARE complexes at the TGN.

The Dsl1 complex is implicated in the tethering of retrograde COPI vesicles directed from the Golgi to the ER (Andag et al. 2001; Reilly et al. 2001). It consists of three subunits (yeast: Dsl1, Tip20, Dsl3; mammals: ZW10, RINT-1, NAG) (Ren et al. 2009; Tripathi et al. 2009). A central acidic domain binds $\delta$ - and $\alpha$-subunits of the COPI coat that function in analogy to the clathrin adaptor and cage components, respectively (Andag et al. 2001;
Reilly et al. 2001). The Dsl1 complex stabilizes a SNARE complex containing Ufelp/syntaxin 18, Sec20p/BNIP1, and Use1p/p31 in the ER (Kraynack et al. 2005; Aoki et al. 2008). Interacting Rab proteins have not been identified. Thus, the Dsl1 complex could tether COPI-coated vesicles to preassembled t-SNARE complexes on the ER. It has been suggested that Dsl1 might also favor COPI vesicle uncoating, exposing the cognate v-SNARE (Zink et al. 2009).

The COG complex is localized to the Golgi, and implicated in retrograde trafficking from the trans-Golgi or an endosomal compartment to the cis-Golgi (Whyte and Munro 2002; Vasile 
et al. 2006; Shestakova et al. 2007). It consists of eight subunits $(\operatorname{Cog} 1-8)$ and forms a bilobe stucture (Ungar et al. 2002). Cog subunits specifically interact with COPI coat components (Suvorova et al. 2002; Zolov and Lupashin 2005). The depletion of the $\operatorname{Cog} 3$ subunit causes the accumulation of Golgi-derived vesicles containing Golgi residents and SNAREs (GS15 and GOS28) and blocks the retrograde traffic of Shiga toxin (Zolov and Lupashin 2005). Cog4 and $\operatorname{Cog} 6$ directly bind syntaxin 5 and the COG complex enhances the stability of syntaxin 5-containing SNARE complexes (Zolov and Lupashin 2005; Shestakova et al. 2007). In addition, several Rab proteins seem to bind to Cogs: Rab1/Yptlp, Rab6/Ypt6p, Rab30, and Rab41 (Suvorova et al. 2002; Fukuda et al. 2008). Remarkably, $\operatorname{Cog} 2$ binds the coiled-coil tether protein p115 and Cog4 binds the SM protein Sly1 (Sohda et al. 2007; Laufman et al. 2009). Both Sly1/Slylp and p115/Usolp directly bind to syntaxin $5 /$ Sed $5 p$ and regulate its activity (Sapperstein et al. 1996; Grabowski and Gallwitz 1997). Furthermore, temperature-sensitive mutants in the yeast p115 (uso1-1) and $\operatorname{cog} 2-t s$ are synthetically lethal supporting the hypothesis that multisubunit and coiled-coil tethers work together in controlling vesicle tethering, docking, and SNARE complex assembly (VanRheenen et al. 1998). One possibility would be that one of the tethers is incorporated during budding and thus ensures that the emerging vesicle does not leave the rims of the Golgi restricting its movement. The second tether then directly affects SNARE complex assembly on the neighboring target membrane. However, the cascade of reactions and the exact functions of these two distinct types of tethers still need to be further established.

In summary, the following reaction pathway emerges. During vesicle budding, distinct coat proteins recruit specific cargo proteins, SNAREs, and Rab-GEFs to the budding site. Rab-GEFs activate specific Rabs, which now bind their effectors, multisubunit and coiledcoil tethers, which in turn activate specific t-SNARE proteins on the target membrane. Then, t-SNAREs are substrates for $\mathrm{v}$-SNARE binding and SNAREpin formation, which is further controlled by another protein family called SM proteins.

\section{SM PROTEINS OF THE GOLGI: Sly1, Vps45}

SM (Seclp/Munc18) proteins represent a family of arch-shaped cytosolic proteins, whose individual members affect SNARE complex assembly at distinct transport steps (Toonen and Verhage 2003). In addition, SM proteins seem to be involved in the proper localization and stabilization of syntaxin/ $\mathrm{Q}_{\mathrm{a}}$-SNAREs. SM proteins are essential for membrane trafficking and their inactivation results in cell death, demonstrating the importance of their interaction with SNAREs. Consequently, SNAREs together with SM proteins have been declared as the universal fusion machinery (Südhof and Rothman 2009). A single SM member can bind several SNARE complexes and serves a subset of transport steps. The SM proteins functioning at the Golgi are Sly1 and Vps45. Sly1/Sly1p binds syntaxin 5/Sed5p in the Golgi and syntaxin 18/ Ufelp in the ER and controls anterograde and retrograde transport between the ER and Golgi and within the Golgi stack (Lupashin et al. 1996; Li et al. 2005). Vps45 binds syntaxin 16/Tlg2p at the TGN and directs transport from early/ recycling endosomes and late endosomes to the TGN (Simonsen et al. 1998; Tang et al. 1998; Struthers et al. 2009). In addition, it binds Pep12 in early endosomes controlling endosomal trafficking (Tellam et al. 1997). SM protein- $\mathrm{Q}_{\mathrm{a}}$-SNARE interactions can stabilize the $\mathrm{Q}_{\mathrm{a}}$-SNARE and vice versa. Vps45p stabilizes Tlg2p, and Sly1p protects Ufelp from degradation (Bryant and James 2001; Braun and Jentsch 2007). With the exception of the Slylp-Sed5p interaction, which seems not to affect Sed5p stability, similar cross stabilizations have been observed for SM proteins and $\mathrm{Q}_{\mathrm{a}}$-SNAREs functioning in regulated exocytosis (Toonen and Verhage 2003; Braun and Jentsch 2007). Thus, it appears that SM proteins can control the amount of different $\mathrm{Q}_{\mathrm{a}}$-SNAREs. Remarkably, the overexpression of SM proteins can boost protein secretion by increasing the size of secretory organelles in certain cells (Peng and Fussenegger 2009). 
In addition to the syntaxin/ $\mathrm{Q}_{\mathrm{a}}$-SNARE interaction, SM proteins bind partially assembled SNARE complexes and stimulate membrane fusion. One of the best-studied systems to understand how SM proteins direct SNARE complex assembly has been regulated exocytosis (Toonen and Verhage 2007). In this case, the neuronal SM protein Munc18-1 has both an inhibitory and stimulatory function (Hata et al. 1993; Misura et al. 2000; Verhage et al. 2000; Shen et al. 2007). Munc18-1 binds the $\mathrm{Q}_{\mathrm{a}}$-SNARE syntaxin 1 in a closed conformation and inhibits t-SNARE (syntaxin 1/SNAP25) and $\mathrm{v}$-/t-SNARE (syntaxin $1 /$ SNAP-25/ VAMP2) complex assembly (Dulubova et al. 1999; Misura et al. 2000). Remarkably, the cognate $\mathrm{v}$-SNARE VAMP2 directly binds Munc18-1 and relieves the inhibition (Xu et al. 2010). In addition, the specific binding of the SM protein to both the $\mathrm{v}$ - and t-SNARE stimulates membrane fusion (Shen et al. 2007). The existence of an inhibitory and a stimulatory binding mode requires distinct binding sites between the SM protein and the syntaxin/ $\mathrm{Q}_{\mathrm{a}}$-SNARE (Südhof and Rothman 2009). Recent data indicate that the stimulatory SM function in the neuronal system depends on the binding of a helical amino-terminal peptide of the $\mathrm{Q}_{\mathrm{a}}$ SNARE into a hydrophobic pocket in domain 1 of the SM protein (Hu et al. 2007; Khvotchev et al. 2007, Shen et al. 2007; Shen et al. 2010). This binding mode seems to be conserved and has been shown for the Slylp-Ufelp, Slyp1Sed5p, and the Vps45p-Tlg2p interactions (Bracher and Weissenhorn 2002; Dulubova et al. 2002; Yamaguchi et al. 2002). It also has been established that the presence of the Tlg2p $\mathrm{N}$-peptide can change the Vps45p-Tlg2p interaction modus (Carpp et al. 2006; Furgason et al. 2009). However, it is still debated whether all SM protein- $\mathrm{Q}_{\mathrm{a}}-\mathrm{SNARE}$ pairs in the Golgi show the same properties as their neuronal counterpart (MacDonald et al. 2010). Nevertheless, it is reasonable to assume that SM proteinSNARE interactions are functionally conserved and that modest changes represent transport step-specific adaptations. In any case, SM proteins bind cognate SNARE complexes. Slylp binds the non $\mathrm{Q}_{\mathrm{a}}$-SNAREs Use1p/pSLT1p and
Sec20p, which are part of the Ufelp complex (Li et al. 2005). It also shows low affinity interactions with the Sed5p t-SNARE components Bos1p and Gos1p and with the v-SNAREs Betlp and Sftlp, and enhances SNAREpin formation (Dascher et al. 1991; Dascher and Balch 1996; Kosodo et al. 2002; Peng and Gallwitz 2002; Peng and Gallwitz 2004). Remarkably, Slylp restricts the interactions of Sed5p with noncognate SNAREs (Peng and Gallwitz 2002). Thus, Sly1 could also act as a molecular shield to prevent the formation of unproductive (nonfusogenic) SNARE complexes. This might be of particular importance in the early secretory pathway, because most SNAREs are tail-anchored proteins, which as newly synthesized proteins are initially inserted into the ER membrane (Kutay et al. 1995; Rabu et al. 2009). Thus, the presence of various SNAREs, which travel through the ER and Golgi to their final destinations, would increase the possibility that noncognate SNARE complexes form. Sly1 could block such adverse interactions.

In summary, SM proteins contribute a layer of specificity to SNARE complex formation and favor membrane fusion, likely by specifically stabilizing cognate SNAREpins. In this context, it is also of note that SM proteins are functionally coupled to tethering proteins. Sly1 directly interacts with the COG tethering complex and both bind syntaxin 5 with distinct binding sites (Laufman et al. 2009). Obliteration of Sly1-Cog binding impairs SNARE pairing and attenuates retrograde Golgi-to-ER transport (Laufman et al. 2009). Thus, the concerted action of SM and tethering proteins controls SNAREpin assembly.

\section{CONCLUDING REMARKS}

For productive fusion to occur, several requirements need to be fulfilled on opposite membranes (Fig. 3). First, during vesicle budding, transport step-specific coat proteins select cargo proteins, specific SNAREs, and a particular Rab-GEF, which activates and recruits a specific Rab protein onto the budding vesicle. Second, the Rab protein binds a specific tether, 


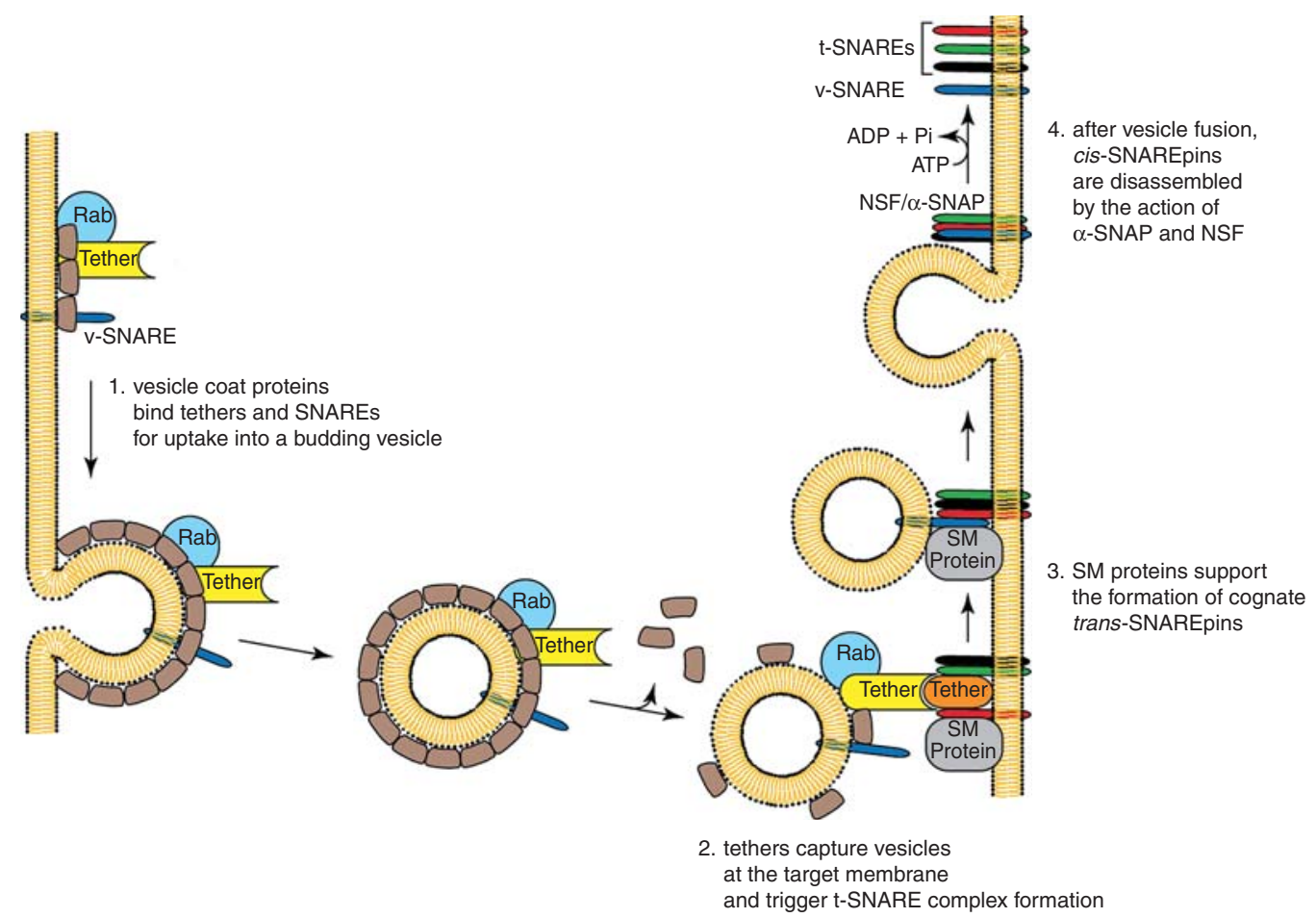

Figure 3. Basic machinery controlling membrane fusion and SNARE recycling. SNAREs and tethers are recruited by vesicle coat components for uptake into a budding vesicle. The initial interaction of a vesicle with its target membrane is mediated by tethering proteins and a small Rab GTPase. Components of the tethering machinery trigger the formation of t-SNARE complexes, which assemble with their cognate v-SNAREs, resulting in the formation of SNAREpins. These events involve SM proteins and finally culminate in membrane fusion, which results in cis-v/t-SNARE complexes. In the presence of SNAPs, ATP-hydrolysis by NSF segregates v- and t-SNAREs for another round of fusion.

which together with the specific SM protein controls t-SNARE complex assembly on the opposite membrane. Third, if a cognate vSNARE is present, it will interact with the t-SNARE while the SM protein provides an additional control level and stimulates SNAREpin assembly, resulting in membrane merger. In the absence of a cognate $\mathrm{v}$-SNARE, stable SNAREpins will not be established and GTP hydrolysis by Rab will eventually release the tether, likely allowing another round of tethering to be initiated. Depending on the length, number, and type of tethers, which link a given vesicle to the Golgi, the vesicle could probe different areas of the Golgi stack, without ever leaving the Golgi, until productive SNAREpins have been established and fusion proceeds.
Thus, various proteins and a potential cascade of reactions controlling SNARE complex assembly have been identified, accompanied by a morphological map showing the distribution of these components within the Golgi stack. However, a functional map at high spatial resolution, resolving transport steps between individual cisternae, is still missing. Because, by its very nature, the transport machinery cycles between individual compartments, it will be necessary to distinguish between inactive and active components on distinct vesicle subpopulation. The identification of various COPI coats and distinct vesicle tethers clearly supports the existence of distinct vesicle populations within the Golgi (Moelleken et al. 2007). Such subpopulations can be isolated 
based on their coat, SNARE, and tether composition (Malsam et al. 2005). Proteomic and lipidomics could then reveal their molecular composition. More importantly, reconstituted fusion assays employing liposomes with distinct t-SNAREs, in the absence or presence of appropriate tethers and SM proteins will show the fusion competence and specificity of the isolated vesicle subpopulations. Concomitantly, the functional/assembly status of t-SNARE and $\mathrm{v}$-/t-SNARE complexes needs to be probed in living cells at the level of individual cisternae. Therefore, t-SNARE components and v-SNAREs could be labeled by fluorescent tags that have the capability to show fluorescence resonance energy transfer. In combination with advanced imaging techniques such as stimulated emission depletion microscopy, far field optical nanoscopy, fluorescence cross correlation microscopy, fluorescence life time imaging, and fluorescence recovery after photobleaching, it will be possible to show where and when t-SNARE complexes form and to which degree assembled $\mathrm{v}-/ \mathrm{t}$ SNARE complexes exist at steady state in cells. Such studies should also detect potential SNARE clusters and their intra-Golgi distribution. With this information in hand, it should be possible to gain detailed insights into where and how distinct vesicle subpopulations fuse, resolving the membrane flow patterns within the Golgi stack and distinguishing between different transport models.

\section{ACKNOWLEDGMENTS}

We apologize to all colleagues, whose work was not discussed because of space limitations. We are grateful to Florian Seiler and Felix Wieland for their critical review of the manuscript and insightful comments.

\section{REFERENCES}

Andag U, Schmitt HD. 2003. Dsllp, an essential component of the Golgi-endoplasmic reticulum retrieval system in yeast, uses the same sequence motif to interact with different subunits of the COPI vesicle coat. J Biol Chem 278: $51722-51734$.

Andag U, Neumann T, Schmitt HD. 2001. The coatomerinteracting protein Dsllp is required for Golgi-to- endoplasmic reticulum retrieval in yeast. J Biol Chem 276: 39150-39160.

Aoki T, Kojima M, Tani K, Tagaya M. 2008. Sec22b-dependent assembly of endoplasmic reticulum Q-SNARE proteins. Biochem J 410: 93-100.

Appenzeller-Herzog C, Hauri HP. 2006. The ER-Golgi intermediate compartment (ERGIC): In search of its identity and function. J Cell Sci 119: 2173-2183.

Arasaki K, Taniguchi M, Tani K, Tagaya M. 2006. RINT-1 regulates the localization and entry of ZW10 to the syntaxin 18 complex. Mol Biol Cell 17: 2780-2788.

Block MR, Glick BS, Wilcox CA, Wieland FT, Rothman JE. 1988. Purification of an N-ethylmaleimide-sensitive protein catalyzing vesicular transport. Proc Natl Acad Sci 85: 7852-7856.

Bracher A, Weissenhorn W. 2002. Structural basis for the Golgi membrane recruitment of Slylp by Sed5p. EMBO J 21: 6114-6124.

Braun S, Jentsch S. 2007. SM-protein-controlled ER-associated degradation discriminates between different SNAREs. EMBO Rep 8: 1176-1182.

Bretscher MS, Munro S. 1993. Cholesterol and the Golgi apparatus. Science 261: 1280-1281.

Bryant NJ, James DE. 2001. Vps45p stabilizes the syntaxin homologue Tlg2 $\mathrm{p}$ and positively regulates SNARE complex formation. EMBO J 20: 3380-3388.

Burri L, Varlamov O, Doege CA, Hofmann K, Beilharz T, Rothman JE, Söllner TH, Lithgow T. 2003. A SNARE required for retrograde transport to the endoplasmic reticulum. Proc Natl Acad Sci 100: 9873-9877.

Cai H, Zhang Y, Pypaert M, Walker L, Ferro-Novick S. 2005. Mutants in trs 120 disrupt traffic from the early endosome to the late Golgi. J Cell Biol 171: 823-833.

Cai H, Yu S, Menon S, Cai Y, Lazarova D, Fu C, Reinisch K, Hay JC, Ferro-Novick S. 2007. TRAPPI tethers COPII vesicles by binding the coat subunit Sec23. Nature 445: 941-944.

Cao X, Barlowe C. 2000. Asymmetric requirements for a Rab GTPase and SNARE proteins in fusion of COPII vesicles with acceptor membranes. J Cell Biol 149: 55-66.

Carpp LN, Ciufo LF, Shanks SG, Boyd A, Bryant NJ. 2006. The Sec1p/Munc18 protein Vps45p binds its cognate SNARE proteins via two distinct modes. J Cell Biol 173: 927-936.

Conibear E, Cleck JN, Stevens TH. 2003. Vps51p mediates the association of the GARP (Vps52/53/54) complex with the late Golgi t-SNARE Tlg1p. Mol Biol Cell 14: $1610-1623$.

Corpet F. 1988. Multiple sequence alignment with hierarchical clustering. Nucleic Acids Res 16: 10881-10890.

Dacks JB, Field MC. 2007. Evolution of the eukaryotic membrane-trafficking system: Origin, tempo and mode. J Cell Sci 120: 2977-2985.

Dascher C, Balch WE. 1996. Mammalian Sly1 regulates syntaxin 5 function in endoplasmic reticulum to Golgi transport. J Biol Chem 271: 15866-15869.

Dascher C, Ossig R, Gallwitz D, Schmitt HD. 1991. Identification and structure of four yeast genes (SLY) that are able to suppress the functional loss of YPT1, a member of the RAS superfamily. Mol Cell Biol 11: 872-885. 
Dilcher M, Veith B, Chidambaram S, Hartmann E, Schmitt HD, Fischer von Mollard G. 2003. Uselp is a yeast SNARE protein required for retrograde traffic to the ER. EMBO J 22: 3664-3674.

Dulubova I, Sugita S, Hill S, Hosaka M, Fernandez I, Sudhof TC, Rizo J. 1999. A conformational switch in syntaxin during exocytosis: Role of munc18. EMBO J 18: 43724382.

Dulubova I, Yamaguchi T, Gao Y, Min SW, Huryeva I, Sudhof TC, Rizo J. 2002. How Tlg2p/syntaxin 16 "snares" Vps45. EMBO J 21: 3620-3631.

Farquhar MG, Palade GE. 1998. The Golgi apparatus: 100 years of progress and controversy. Trends Cell Biol 8: $2-10$.

Fasshauer D, Margittai M. 2004. A transient N-terminal interaction of SNAP-25 and syntaxin nucleates SNARE assembly. J Biol Chem 279: 7613-7621.

Fasshauer D, Otto H, Eliason WK, Jahn R, Brunger AT. 1997. Structural changes are associated with soluble N-ethylmaleimide-sensitive fusion protein attachment protein receptor complex formation. J Biol Chem 272: 28036-28041.

Fasshauer D, Sutton RB, Brunger AT, Jahn R. 1998. Conserved structural features of the synaptic fusion complex: SNARE proteins reclassified as Q- and R-SNAREs. Proc Natl Acad Sci 95: 15781-15786.

Fridmann-Sirkis Y, Kent HM, Lewis MJ, Evans PR, Pelham HR. 2006. Structural analysis of the interaction between the SNARE Tlg1 and Vps51. Traffic 7: 182-190.

Frigerio G. 1998. The Saccharomyces cerevisiae early secretion mutant tip20 is synthetic lethal with mutants in yeast coatomer and the SNARE proteins Sec22p and Ufelp. Yeast 14: 633-646.

Fukasawa M, Varlamov O, Eng WS, Sollner TH, Rothman JE. 2004. Localization and activity of the SNARE Ykt6 determined by its regulatory domain and palmitoylation. Proc Natl Acad Sci 101: 4815-4820.

Fukuda M, Kanno E, Ishibashi K, Itoh T. 2008. Large scale screening for novel rab effectors reveals unexpected broad Rab binding specificity. Mol Cell Proteomics 7: 10311042.

Furgason ML, MacDonald C, Shanks SG, Ryder SP, Bryant NJ, Munson M. 2009. The N-terminal peptide of the syntaxin Tlg2p modulates binding of its closed conformation to Vps45p. Proc Natl Acad Sci 106: 14303-14308.

Ganley IG, Espinosa E, Pfeffer SR. 2008. A syntaxin 10SNARE complex distinguishes two distinct transport routes from endosomes to the trans-Golgi in human cells. J Cell Biol 180: 159-172.

Glick BS, Luini A. 2011. Models for Golgi traffic: A critical assessment. Cold Spring Harb Perspect Biol 3: a005215.

Grabowski R, Gallwitz D. 1997. High-affinity binding of the yeast cis-Golgi t-SNARE, Sed5p, to wild-type and mutant Sly1p, a modulator of transport vesicle docking. FEBS Lett 411: 169-172.

Grote E, Baba M, Ohsumi Y, Novick PJ. 2000. Geranylgeranylated SNAREs are dominant inhibitors of membrane fusion. J Cell Biol 151: 453-466.

Hardwick KG, Pelham HR. 1992. SED5 encodes a 39-kD integral membrane protein required for vesicular transport between the ER and the Golgi complex. J Cell Biol 119: 513-521.

Hata Y, Slaughter CA, Sudhof TC. 1993. Synaptic vesicle fusion complex contains unc-18 homologue bound to syntaxin. Nature 366: 347-351.

Hatsuzawa K, Hirose H, Tani K, Yamamoto A, Scheller RH, Tagaya M. 2000. Syntaxin 18, a SNAP receptor that functions in the endoplasmic reticulum, intermediate compartment, and cis-Golgi vesicle trafficking. J Biol Chem 275: 13713-13720.

Hirose H, Arasaki K, Dohmae N, Takio K, Hatsuzawa K, Nagahama M, Tani K, Yamamoto A, Tohyama M, Tagaya M. 2004. Implication of ZW10 in membrane trafficking between the endoplasmic reticulum and Golgi. EMBO J 23: $1267-1278$.

Holthuis JC, Nichols BJ, Dhruvakumar S, Pelham HR. 1998. Two syntaxin homologues in the TGN/endosomal system of yeast. EMBO J 17: 113-126.

Honda A, Al-Awar OS, Hay JC, Donaldson JG. 2005. Targeting of Arf- 1 to the early Golgi by membrin, an ER-Golgi SNARE. J Cell Biol 168: 1039-1051.

Hu C, Ahmed M, Melia TJ, Sollner TH, Mayer T, Rothman JE. 2003. Fusion of cells by flipped SNAREs. Science 300: 1745-1749.

Hu SH, Latham CF, Gee CL, James DE, Martin JL. 2007. Structure of the Munc18c/Syntaxin 4 N-peptide complex defines universal features of the $\mathrm{N}$-peptide binding mode of Sec1/Munc18 proteins. Proc Natl Acad Sci 104: $8773-8778$.

Jahn R, Scheller RH. 2006. SNAREs-engines for membrane fusion. Nat Rev Mol Cell Biol 7: 631-643.

Jones S, Newman C, Liu F, Segev N. 2000. The TRAPP complex is a nucleotide exchanger for Ypt1 and Ypt31/32. Mol Biol Cell 11: 4403-4411.

Khvotchev M, Dulubova I, Sun J, Dai H, Rizo J, Sudhof TC. 2007. Dual modes of Munc18-1/SNARE interactions are coupled by functionally critical binding to syntaxin-1 N terminus. J Neurosci 27: 12147-12155.

Kienle N, Kloepper TH, Fasshauer D. 2009. Differences in the SNARE evolution of fungi and metazoa. Biochem Soc Trans 37: 787-791.

Kim YG, Raunser S, Munger C, Wagner J, Song YL, Cygler M, Walz T, Oh BH, Sacher M. 2006. The architecture of the multisubunit TRAPP I complex suggests a model for vesicle tethering. Cell 127: 817-830.

Kloepper TH, Kienle CN, Fasshauer D. 2007. An elaborate classification of SNARE proteins sheds light on the conservation of the eukaryotic endomembrane system. Mol Biol Cell 18: 3463-3471.

Kosodo Y, Noda Y, Adachi H, Yoda K. 2002. Binding of Slyl to Sed5 enhances formation of the yeast early Golgi SNARE complex. J Cell Sci 115: 3683-3691.

Kraynack BA, Chan A, Rosenthal E, Essid M, Umansky B, Waters MG, Schmitt HD. 2005. Dsllp, Tip20p, and the novel Dsl3(Sec39) protein are required for the stability of the Q/t-SNARE complex at the endoplasmic reticulum in yeast. Mol Biol Cell 16: 3963-3977.

Kutay U, Ahnert-Hilger G, Hartmann E, Wiedenmann B, Rapoport TA. 1995. Transport route for synaptobrevin via a novel pathway of insertion into the endoplasmic reticulum membrane. EMBO J 14: 217-223. 
Lang T, Bruns D, Wenzel D, Riedel D, Holroyd P, Thiele C, Jahn R. 2001. SNAREs are concentrated in cholesteroldependent clusters that define docking and fusion sites for exocytosis. EMBO J 20: 2202-2213.

Laufman O, Kedan A, Hong W, Lev S. 2009. Direct interaction between the COG complex and the SM protein, Slyl, is required for Golgi SNARE pairing. $E M B O J$ 28: 2006-2017.

Lee SY, Yang JS, Hong W, Premont RT, Hsu VW. 2005. ARFGAP1 plays a central role in coupling COPI cargo sorting with vesicle formation. J Cell Biol 168: 281-290.

Lewis MJ, Rayner JC, Pelham HR. 1997. A novel SNARE complex implicated in vesicle fusion with the endoplasmic reticulum. EMBO J 16: 3017-3024.

Li Y, Gallwitz D, Peng R. 2005. Structure-based functional analysis reveals a role for the SM protein Slylp in retrograde transport to the endoplasmic reticulum. Mol Biol Cell 16: 3951-3962.

Liewen H, Meinhold-Heerlein I, Oliveira V, Schwarzenbacher R, Luo G, Wadle A, Jung M, Pfreundschuh M, Stenner-Liewen F. 2005. Characterization of the human GARP (Golgi associated retrograde protein) complex. Exp Cell Res 306: 24-34.

Lupashin VV, Hamamoto S, Schekman RW. 1996. Biochemical requirements for the targeting and fusion of ER-derived transport vesicles with purified yeast Golgi membranes. J Cell Biol 132: 277-289.

MacDonald C, Munson M, Bryant NJ. 2010. Autoinhibition of SNARE complex assembly by a conformational switch represents a conserved feature of syntaxins. Biochem Soc Trans 38: 209-212.

Mallard F, Tang BL, Galli T, Tenza D, Saint-Pol A, Yue X, Antony C, Hong W, Goud B, Johannes L. 2002. Early/ recycling endosomes-to-TGN transport involves two SNARE complexes and a Rab6 isoform. J Cell Biol 156: 653-664.

Malsam J, Satoh A, Pelletier L, Warren G. 2005. Golgin tethers define subpopulations of COPI vesicles. Science 307: 1095-1098.

Malsam J, Kreye S, Sollner TH. 2008. Membrane fusion: SNAREs and regulation. Cell Mol Life Sci 65: 2814-2832.

Matsuoka K, Morimitsu Y, Uchida K, Schekman R. 1998. Coat assembly directs v-SNARE concentration into synthetic COPII vesicles. Mol Cell 2: 703-708.

Mayer A, Wickner W, Haas A. 1996. Sec18p (NSF)-driven release of Sec17p (alpha-SNAP) can precede docking and fusion of yeast vacuoles. Cell 85: 83-94.

McNew JA, Parlati F, Fukuda R, Johnston RJ, Paz K, Paumet F, Söllner TH, Rothman JE. 2000a. Compartmental specificity of cellular membrane fusion encoded in SNARE proteins. Nature 407: 153-159.

McNew JA, Weber T, Parlati F, Johnston RJ, Melia TJ, Söllner TH, Rothman JE. 2000b. Close is not enough: SNAREdependent membrane fusion requires an active mechanism that transduces force to membrane anchors. J Cell Biol 150: 105-117.

Meiringer CT, Auffarth K, Hou H, Ungermann C. 2008. Depalmitoylation of Ykt6 prevents its entry into the multivesicular body pathway. Traffic 9: 1510-1521.

Melia TJ, Weber T, McNew JA, Fisher LE, Johnston RJ, Parlati F, Mahal LK, Sollner TH, Rothman JE. 2002.
Regulation of membrane fusion by the membraneproximal coil of the t-SNARE during zippering of SNAREpins. J Cell Biol 158: 929-940.

Misura KM, Scheller RH, Weis WI. 2000. Three-dimensional structure of the neuronal-Sec1-syntaxin la complex. Nature 404: 355-362.

Moelleken J, Malsam J, Betts MJ, Movafeghi A, Reckmann I, Meissner I, Hellwig A, Russell RB, Sollner T, Brugger B, et al. 2007. Differential localization of coatomer complex isoforms within the Golgi apparatus. Proc Natl Acad Sci 104: $4425-4430$

Morozova N, Liang Y, Tokarev AA, Chen SH, Cox R, Andrejic J, Lipatova Z, Sciorra VA, Emr SD, Segev N. 2006. TRAPPII subunits are required for the specificity switch of a Ypt-Rab GEF. Nat Cell Biol 8: 1263-1269.

Mossessova E, Bickford LC, Goldberg J. 2003. SNARE selectivity of the COPII coat. Cell 114: 483-495.

Munro S. 1995. An investigation of the role of transmembrane domains in Golgi protein retention. $E M B O J 14$ : 4695-4704.

Munro S. 2011. The Golgin coiled-coil proteins of the Golgi apparatus. Cold Spring Harb Perspect Biol doi: 10.1101/ cshperspect.a005256.

Nagahama M, Orci L, Ravazzola M, Amherdt M, Lacomis L, Tempst P, Rothman JE, Sollner TH. 1996. A v-SNARE implicated in intra-Golgi transport. J Cell Biol 133: 507-516.

Newman AP, Ferro-Novick S. 1987. Characterization of new mutants in the early part of the yeast secretory pathway isolated by a $[3 \mathrm{H}]$ mannose suicide selection. J Cell Biol 105: 1587-1594.

Newman AP, Shim J, Ferro-Novick S. 1990. BET1, BOS1, and SEC22 are members of a group of interacting yeast genes required for transport from the endoplasmic reticulum to the Golgi complex. Mol Cell Biol 10: 3405-3414.

Orci L, Ravazzola M, Volchuk A, Engel T, Gmachl M, Amherdt M, Perrelet A, Sollner TH, Rothman JE. 2000. Anterograde flow of cargo across the golgi stack potentially mediated via bidirectional "percolating" COPI vesicles. Proc Natl Acad Sci 97: 10400-10405.

Paek I, Orci L, Ravazzola M, Erdjument-Bromage H, Amherdt M, Tempst P, Sollner TH, Rothman JE. 1997. ERS-24, a mammalian v-SNARE implicated in vesicle traffic between the ER and the Golgi. J Cell Biol 137: 1017-1028.

Parlati F, McNew JA, Fukuda R, Miller R, Sollner TH, Rothman JE. 2000. Topological restriction of SNAREdependent membrane fusion. Nature 407: 194-198.

Parlati F, Varlamov O, Paz K, McNew JA, Hurtado D, Sollner TH, Rothman JE. 2002. Distinct SNARE complexes mediating membrane fusion in Golgi transport based on combinatorial specificity. Proc Natl Acad Sci 99: 5424-5429.

Paumet F, Brügger B, Parlati F, McNew JA, Söllner TH, Rothman JE. 2001. A t-SNARE of the endocytic pathway must be activated for fusion. J Cell Biol 155: 961-968.

Peng RW, Fussenegger M. 2009. Molecular engineering of exocytic vesicle traffic enhances the productivity of Chinese hamster ovary cells. Biotechnol Bioeng 102: $1170-1181$. 
Peng R, Gallwitz D. 2002. Sly1 protein bound to Golgi syntaxin Sed5p allows assembly and contributes to specificity of SNARE fusion complexes. J Cell Biol 157: 645-655.

Peng R, Gallwitz D. 2004. Multiple SNARE interactions of an SM protein: Sed5p/Slylp binding is dispensable for transport. EMBO J 23: 3939-3949.

Perez-Victoria FJ, Bonifacino JS. 2009. Dual roles of the mammalian GARP complex in tethering and SNARE complex assembly at the trans-golgi network. Mol Cell Biol 29: 5251-5263.

Pobbati AV, Stein A, Fasshauer D. 2006. N- to C-terminal SNARE complex assembly promotes rapid membrane fusion. Science 313: 673-676.

Poon PP, Cassel D, Spang A, Rotman M, Pick E, Singer RA, Johnston GC. 1999. Retrograde transport from the yeast Golgi is mediated by two ARF GAP proteins with overlapping function. $E M B O J$ 18: 555-564.

Popoff V, Adolf F, Brügger B, Wieland F. 2011. COPI budding within the Golgi stack. Cold Spring Harb Perspect Biol 3: a005231.

Quenneville NR, Chao TY, McCaffery JM, Conibear E. 2006. Domains within the GARP subunit Vps54 confer separate functions in complex assembly and early endosome recognition. Mol Biol Cell 17: 1859-1870.

Rabu C, Schmid V, Schwappach B, High S. 2009. Biogenesis of tail-anchored proteins: The beginning for the end? J Cell Sci 122: 3605-3612.

Ram RJ, Li B, Kaiser CA. 2002. Identification of Sec36p, Sec37p, and Sec38p: Components of yeast complex that contains Sec34p and Sec35p. Mol Biol Cell 13: 1484-1500.

Rayner JC, Pelham HR. 1997. Transmembrane domaindependent sorting of proteins to the ER and plasma membrane in yeast. EMBO J 16: 1832-1841.

Reggiori F, Black MW, Pelham HR. 2000. Polar transmembrane domains target proteins to the interior of the yeast vacuole. Mol Biol Cell 11: 3737-3749.

Reilly BA, Kraynack BA, VanRheenen SM, Waters MG. 2001. Golgi-to-endoplasmic reticulum (ER) retrograde traffic in yeast requires Dsllp, a component of the ER target site that interacts with a COPI coat subunit. Mol Bio Cell 12: 3783-3796.

Rein U, Andag U, Duden R, Schmitt HD, Spang A. 2002. ARF-GAP-mediated interaction between the ER-Golgi v-SNAREs and the COPI coat. J Cell Biol 157: 395-404.

Ren Y, Yip CK, Tripathi A, Huie D, Jeffrey PD, Walz T, Hughson FM. 2009. A structure-based mechanism for vesicle capture by the multisubunit tethering complex Dsll. Cell 139: 1119-1129.

Sacher M, Barrowman J, Wang W, Horecka J, Zhang Y, Pypaert M, Ferro-Novick S. 2001. TRAPP I implicated in the specificity of tethering in ER-to-Golgi transport. Mol Cell 7: 433-442.

Sapperstein SK, Lupashin VV, Schmitt HD, Waters MG. 1996. Assembly of the ER to Golgi SNARE complex requires Uso1p. J Cell Biol 132: 755-767.

Shen J, Tareste DC, Paumet F, Rothman JE, Melia TJ. 2007. Selective activation of cognate SNAREpins by Secl/ Munc18 proteins. Cell 128: 183-195.

Shen J, Rathore SS, Khandan L, Rothman JE. 2010. SNARE bundle and syntaxin $\mathrm{N}$-peptide constitute a minimal complement for Munc18-1 activation of membrane fusion. J Cell Biol 190: 55-63.

Shestakova A, Suvorova E, Pavliv O, Khaidakova G, Lupashin V. 2007. Interaction of the conserved oligomeric Golgi complex with t-SNARE Syntaxin5a/Sed5 enhances intra-Golgi SNARE complex stability. J Cell Biol 179: 1179-1192.

Shim J, Newman AP, Ferro-Novick S. 1991. The BOS1 gene encodes an essential $27-\mathrm{kD}$ putative membrane protein that is required for vesicular transport from the ER to the Golgi complex in yeast. J Cell Biol 113: 55-64.

Shorter J, Beard MB, Seemann J, Dirac-Svejstrup AB, Warren G. 2002. Sequential tethering of Golgins and catalysis of SNAREpin assembly by the vesicle-tethering protein p115. J Cell Biol 157: 45-62.

Sieber JJ, Willig KI, Kutzner C, Gerding-Reimers C, Harke B, Donnert G, Rammner B, Eggeling C, Hell SW, Grubmuller $\mathrm{H}$, et al. 2007. Anatomy and dynamics of a supramolecular membrane protein cluster. Science 317: 1072-1076.

Simonsen A, Bremnes B, Ronning E, Aasland R, Stenmark H. 1998. Syntaxin-16, a putative Golgi t-SNARE. Eur J Cell Biol 75: 223-231.

Siniossoglou S, Pelham HR. 2001. An effector of Ypt6p binds the SNARE Tlg1p and mediates selective fusion of vesicles with late Golgi membranes. $E M B O J$ 20: 5991-5998.

Siniossoglou S, Pelham HR. 2002. Vps51p links the VFT complex to the SNARE Tlg1p. J Biol Chem 277: 4831848324.

Sohda M, Misumi Y, Yoshimura S, Nakamura N, Fusano T, Ogata S, Sakisaka S, Ikehara Y. 2007. The interaction of two tethering factors, p115 and COG complex, is required for Golgi integrity. Traffic 8: 270-284.

Söllner T, Bennett MK, Whiteheart SW, Scheller RH, Rothman JE. 1993a. A protein assembly-disassembly pathway in vitro that may correspond to sequential steps of synaptic vesicle docking, activation, and fusion. Cell 75: 409-418.

Söllner T, Whiteheart SW, Brunner M, Erdjument-Bromage H, Geromanos S, Tempst P, Rothman JE. 1993b. SNAP receptors implicated in vesicle targeting and fusion. Nature 362: 318-324.

Spang A, Schekman R. 1998. Reconstitution of retrograde transport from the Golgi to the ER in vitro. J Cell Biol 143: $589-599$.

Springer S, Schekman R. 1998. Nucleation of COPII vesicular coat complex by endoplasmic reticulum to Golgi vesicle SNAREs. Science 281: 698-700.

Stein A, Weber G, Wahl MC, Jahn R. 2009. Helical extension of the neuronal SNARE complex into the membrane. Nature 460: 525-528.

Stenmark H. 2009. Rab GTPases as coordinators of vesicle traffic. Nat Rev Mol Cell Biol 10: 513-525.

Struthers MS, Shanks SG, MacDonald C, Carpp LN, Drozdowska AM, Kioumourtzoglou D, Furgason ML, Munson M, Bryant NJ. 2009. Functional homology of mammalian syntaxin 16 and yeast $\operatorname{Tlg} 2 \mathrm{p}$ reveals a conserved regulatory mechanism. J Cell Sci 122: 2292-2299. 
Subramaniam VN, Peter F, Philp R, Wong SH, Hong W. 1996. GS28, a 28-kilodalton Golgi SNARE that participates in ER-Golgi transport. Science 272: 1161-1163.

Südhof TC, Rothman JE. 2009. Membrane fusion: Grappling with SNARE and SM proteins. Science 323: 474-477.

Sutton RB, Fasshauer D, Jahn R, Brunger AT. 1998. Crystal structure of a SNARE complex involved in synaptic exocytosis at $2.4 \AA$ resolution. Nature 395: 347-353.

Suvorova ES, Duden R, Lupashin VV. 2002. The Sec34/ Sec35p complex, a Yptlp effector required for retrograde intra-Golgi trafficking, interacts with Golgi SNAREs and COPI vesicle coat proteins. J Cell Biol 157: 631-643.

Sztul E, Lupashin V. 2009. Role of vesicle tethering factors in the ER-Golgi membrane traffic. FEBS Lett 583: 3770 3783.

Tang BL, Low DY, Lee SS, Tan AE, Hong W. 1998. Molecular cloning and localization of human syntaxin 16 , a member of the syntaxin family of SNARE proteins. Biochem Biophys Res Commun 242: 673-679.

Tellam JT, James DE, Stevens TH, Piper RC. 1997. Identification of a mammalian Golgi Seclp-like protein, mVps45. J Biol Chem 272: 6187-6193.

Toonen RF, Verhage M. 2003. Vesicle trafficking: Pleasure and pain from SM genes. Trends Cell Biol 13: 177-186.

Toonen RF, Verhage M. 2007. Munc18-1 in secretion: Lonely Munc joins SNARE team and takes control. Trends Neurosci 30: 564-572.

Tripathi A, Ren Y, Jeffrey PD, Hughson FM. 2009. Structural characterization of Tip20p and Dsllp, subunits of the Dsllp vesicle tethering complex. Nat Struct Mol Biol 16: 114-123.

Tsui MM, Tai WC, Banfield DK. 2001. Selective formation of Sed5p-containing SNARE complexes is mediated by combinatorial binding interactions. Mol Biol Cell 12: 521-538.

Ungar D, Oka T, Brittle EE, Vasile E, Lupashin VV, Chatterton JE, Heuser JE, Krieger M, Waters MG. 2002. Characterization of a mammalian Golgi-localized protein complex, COG, that is required for normal Golgi morphology and function. J Cell Biol 157: 405-415.

VanRheenen SM, Cao X, Lupashin VV, Barlowe C, Waters MG. 1998. Sec35p, a novel peripheral membrane protein, is required for ER to Golgi vesicle docking. J Cell Biol 141: 1107-1119.

Varlamov O, Volchuk A, Rahimian V, Doege CA, Paumet F, Eng WS, Arango N, Parlati F, Ravazzola M, Orci L, et al. 2004. i-SNAREs: Inhibitory SNAREs that fine-tune the specificity of membrane fusion. J Cell Biol 164: 79-88.

Vasile E, Oka T, Ericsson M, Nakamura N, Krieger M. 2006 IntraGolgi distribution of the Conserved Oligomeric Golgi (COG) complex. Exp Cell Res 312: 3132-3141.

Verhage M, Maia AS, Plomp JJ, Brussaard AB, Heeroma JH, Vermeer H, Toonen RF, Hammer RE, van den Berg TK, Missler M, et al. 2000. Synaptic assembly of the brain in the absence of neurotransmitter secretion. Science 287: 864-869.

Volchuk A, Ravazzola M, Perrelet A, Eng WS, Di Liberto M, Varlamov O, Fukasawa M, Engel T, Sollner TH, Rothman
Organization of SNAREs within the Golgi Stack

JE, et al. 2004. Countercurrent distribution of two distinct SNARE complexes mediating transport within the Golgi stack. Mol Biol Cell 15: 1506-1518.

Wang W, Sacher M, Ferro-Novick S. 2000. TRAPP stimulates guanine nucleotide exchange on Yptlp. J Cell Biol 151: 289-296.

Weber T, Zemelman BV, McNew JA, Westermann B, Gmachl M, Parlati F, Sollner TH, Rothman JE. 1998. SNAREpins: Minimal machinery for membrane fusion. Cell 92: 759-772.

Whiteheart SW, Griff IC, Brunner M, Clary DO, Mayer T, Buhrow SA, Rothman JE. 1993. SNAP family of NSF attachment proteins includes a brain-specific isoform. Nature 362: 353-355.

Whyte JR, Munro S. 2002. Vesicle tethering complexes in membrane traffic. J Cell Sci 115: 2627-2637.

Xu D, Hay JC. 2004. Reconstitution of COPII vesicle fusion to generate a pre-Golgi intermediate compartment. J Cell Biol 167: 997-1003.

Xu D, Joglekar AP, Williams AL, Hay JC. 2000. Subunit structure of a mammalian ER/Golgi SNARE complex. J Biol Chem 275: 39631-39639.

Xu Y, Martin S, James DE, Hong W. 2002. GS15 forms a SNARE complex with syntaxin 5, GS28, and Ykt6 and is implicated in traffic in the early cisternae of the Golgi apparatus. Mol Biol Cell 13: 3493-3507.

Xu Y, Su L, Rizo J. 2010. Binding of Munc18-1 to synaptobrevin and to the SNARE four-helix bundle. Biochemistry 49: $1568-1576$.

Yamaguchi T, Dulubova I, Min SW, Chen X, Rizo J, Sudhof TC. 2002. Sly1 binds to Golgi and ER syntaxins via a conserved N-terminal peptide motif. Dev Cell 2: 295-305.

Yamasaki A, Menon S, Yu S, Barrowman J, Meerloo T, Oorschot V, Klumperman J, Satoh A, Ferro-Novick S. 2009. mTrs130 is a component of a mammalian TRAPPII complex, a Rab1 GEF that binds to COPI-coated vesicles. Mol Biol Cell 20: 4205-4215.

Zhang T, Hong W. 2001. Ykt6 forms a SNARE complex with syntaxin 5, GS28, and Bet1 and participates in a late stage in endoplasmic reticulum-Golgi transport. J Biol Chem 276: $27480-27487$.

Zhang T, Wong SH, Tang BL, Xu Y, Peter F, Subramaniam VN, Hong W. 1997. The mammalian protein (rbet1) homologous to yeast Betlp is primarily associated with the pre-Golgi intermediate compartment and is involved in vesicular transport from the endoplasmic reticulum to the Golgi apparatus. J Cell Biol 139: 1157-1168.

Zink S, Wenzel D, Wurm CA, Schmitt HD. 2009. A link between ER tethering and COP-I vesicle uncoating. Dev Cell 17: 403-416.

Zolov SN, Lupashin VV. 2005. Cog3p depletion blocks vesicle-mediated Golgi retrograde trafficking in HeLa cells. J Cell Biol 168: 747-759.

Zwilling D, Cypionka A, Pohl WH, Fasshauer D, Walla PJ, Wahl MC, Jahn R. 2007. Early endosomal SNAREs form a structurally conserved SNARE complex and fuse liposomes with multiple topologies. EMBO J 26: 9-18. 


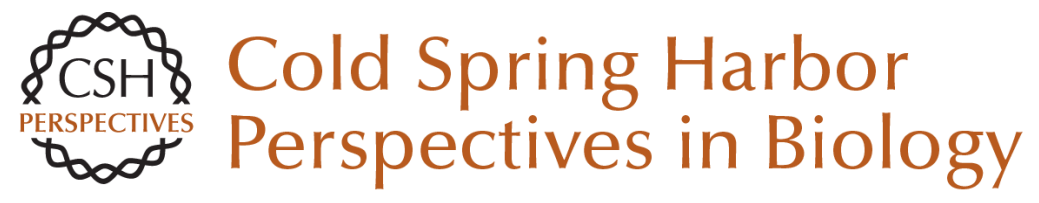

\section{Organization of SNAREs within the Golgi Stack}

Jörg Malsam and Thomas H. Söllner

Cold Spring Harb Perspect Biol 2011; doi: 10.1101/cshperspect.a005249 originally published online July 18,2011

\section{Subject Collection The Golgi}

Structure of Golgi Transport Proteins

Daniel Kümmel and Karin M. Reinisch

\section{Golgi Biogenesis}

Yanzhuang Wang and Joachim Seemann

Golgi Glycosylation and Human Inherited

Diseases

Hudson H. Freeze and Bobby G. Ng

Models for Golgi Traffic: A Critical Assessment

Benjamin S. Glick and Alberto Luini

\section{Architecture of the Mammalian Golgi} Judith Klumperman

Evolution and Diversity of the Golgi Mary J. Klute, Paul Melançon and Joel B. Dacks

Evolutionary Forces Shaping the Golgi

Glycosylation Machinery: Why Cell Surface

Glycans Are Universal to Living Cells Ajit Varki

Golgi Positioning

Smita Yadav and Adam D. Linstedt
Golgi and Related Vesicle Proteomics: Simplify to Identify

Joan Gannon, John J.M. Bergeron and Tommy Nilsson

Organization of SNAREs within the Golgi Stack Jörg Malsam and Thomas H. Söllner

Golgi during Development Weimin Zhong

Entry and Exit Mechanisms at the cis-Face of the Golgi Complex Andrés Lorente-Rodríguez and Charles Barlowe

COPI Budding within the Golgi Stack Vincent Popoff, Frank Adolf, Britta Brügger, et al.

Mechanisms of Protein Retention in the Golgi David K. Banfield

The Golgin Coiled-Coil Proteins of the Golgi

Apparatus Sean Munro

Signaling at the Golgi Peter Mayinger

For additional articles in this collection, see http://cshperspectives.cshlp.org/cgi/collection/

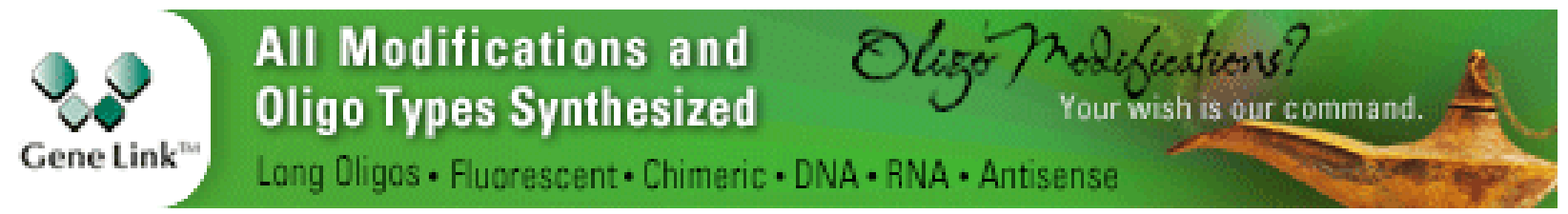

Copyright @ 2011 Cold Spring Harbor Laboratory Press; all rights reserved 